\title{
The effects of fluid restriction on hydration status and subjective feelings in man
}

\author{
Susan M. Shirreffs ${ }^{1 *}$, Stuart J. Merson ${ }^{1}$, Susan M. Fraser ${ }^{2}$ and David T. Archer ${ }^{2}$ \\ ${ }^{1}$ School of Sport and Exercise Sciences, Loughborough University, Loughborough LE11 3TU, UK \\ ${ }^{2}$ Biomedical Sciences, University Medical School, Foresterhill, Aberdeen AB25 2ZD, UK
}

(Received 23 July 2003 - Revised 23 February 2004 - Accepted 29 February 2004)

\begin{abstract}
Hydration status and the effects of hypohydration have been the topic of much public and scientific debate in recent years. While many physiological responses to hypohydration have been studied extensively, the subjective responses to hypohydration have largely been ignored. The present investigation was designed to investigate the physiological responses and subjective feelings resulting from 13, 24 and $37 \mathrm{~h}$ of fluid restriction (FR) and to compare these with a euhydration (EU) trial of the same duration in fifteen healthy volunteers. The volunteers were nine men and six women of mean age 30 (SD 12) years and body mass 71.5 (SD 13.4) kg. Urine and blood samples were collected and subjective feelings recorded on a $100 \mathrm{~mm}$ verbally anchored questionnaire at intervals throughout the investigation. In the EU trial the subjects maintained their normal diet. Body mass decreased by 2.7 (SD 0.6) $\%$ at $37 \mathrm{~h}$ in the FR trial and did not change significantly in the EU trial. Food intake in the FR trial ( $n$ 10) provided an estimated water intake of 487 (SD 335) ml and urinary losses ( $n$ 15) amounted to 1.37 (SD 0.39) litres. This is in comparison with an estimated water intake of 3168 (SD 1167) ml and a urinary loss of 2.76 (SD 1.11) litres in the EU trial. Plasma osmolality and angiotensin II concentrations increased from $0-37 \mathrm{~h}$ with FR. Plasma volume decreased linearly throughout the FR trial amounting to a $6 \cdot 2$ (SD 5.1) \% reduction by $37 \mathrm{~h}$. Thirst increased from $0-13 \mathrm{~h}$ of FR then did not increase further $(P>0.05)$. The subjects reported feelings of headache during the FR trial and also that their ability to concentrate and their alertness were reduced.
\end{abstract}

Fluid restriction: Thirst: Subjective feelings

Hydration status, water consumption and the effects of hypohydration have been the topic of much public and scientific debate in recent years. Much of the popular press in this area suggests that a conscious effort is required by an individual if they are to drink sufficient fluid to maintain a state of body water balance. While many physiological responses to hypohydration have been studied extensively, the perceived subjective responses to hypohydration have largely been ignored to date. This is particularly relevant if there is the possibility that it is 'easy' for an individual to inadvertently restrict their fluid intake over a number of days and thus to become hypohydrated. The present study aimed to investigate this possibility.

The balance between the loss and gain of fluids maintains the body water within relatively narrow limits (Andersson, 1978). The routes of water loss from the body are the urinary system, the skin, the gastrointestinal tract and the respiratory surfaces. The primary avenues for restoration of water balance are fluid and food ingestion (Greenleaf, 1992), with water of oxidation making a minor contribution. The volumes of water that individuals obtain from food and drinks are highly variable, although it is generally reported that the majority normally comes from liquids with a smaller, although still significant, proportion from solid foods (for example, see Documenta Geigy, 1962).

Body-water loss in man results in fluid losses from both the intracellular and extracellular fluid compartments (Costill et al. 1976). The fluid losses, however, can cause very different effects on the remaining body water pools depending on the type of water loss that occurs (Jennett, 2001; Lote, 2001). Hypotonic water loss, as can occur with sweating, results in an increase in body fluid tonicity, while isotonic loss causes a net fluid loss, but no increase or decrease in body fluid tonicity. Hypertonic fluid losses, as can occur with the production of a concentrated urine, cause a reduction in body fluid tonicity.

Fluid restriction (FR) for periods of up to $24 \mathrm{~h}$ has been commonly used to induce experimental dehydration (Phillips et al. 1984; Pedersen et al. 2001). However, the effect of FR for periods greater than $24 \mathrm{~h}$ and the time course of these changes have not been extensively addressed.

The purpose of the present study was to assess the time course of the response to $37 \mathrm{~h}$ of FR and to compare this 
with a euhydration (EU) trial of the same duration. In addition to observing physiological measures of hydration status, the present study aimed to investigate selected subjective feelings, such as feelings of headache, that are commonly reported to be caused by hypohydration. Subjects were given full control of their dietary intake whilst following the request to abstain from all fluid intake and to ingest foods that had a low water content. The present study, therefore, is a descriptive study reporting the effects of mild hypohydration induced voluntarily in healthy individuals.

\section{Methods}

\section{Subjects}

Fifteen subjects (nine male and six female; mean age 30 (SD 12) years; body mass 71.5 (SD 13.4) kg) volunteered to take part in the present study which had been approved by the Grampian Research Ethics Committee. The nature of the experiment was explained to the subjects and written consent to participate was obtained. Each subject completed two experimental trials, which were undertaken in randomised order. In one trial they restricted their fluid intake (FR trial) and in the other they followed their normal fluid ingestion pattern to remain euhydrated throughout (EU trial).

\section{Pre-trial standardisation}

For the initial measurement $(0 \mathrm{~h})$ in both trials, the subjects reported to the laboratory in the evening, at the same time in both trials, having fasted for at least $4 \mathrm{~h}$. Water $(500 \mathrm{ml})$ was consumed $2 \mathrm{~h}$ before arrival. Food and activity were recorded for the $24 \mathrm{~h}$ before the first trial and these were reproduced over the $24 \mathrm{~h}$ before the second trial. The subjects were instructed to avoid alcohol consumption or strenuous exercise during this $24 \mathrm{~h}$ period.

\section{Experimental protocol}

In the EU trial, the subjects were asked to consume their normal diet and to follow their normal fluid ingestion pattern. Upon arrival at the laboratory, the subjects emptied their bladder. The volume of the total void was recorded and a sample retained for analysis. Body mass was then measured nude to the nearest $10 \mathrm{~g}$ on a beam balance (Marsdens, London, UK) and, following $15 \mathrm{~min}$ of seated rest, a baseline blood sample $(6.5 \mathrm{ml})$ was collected without stasis from an antecubital vein. During the 15 min of seated rest, subjective feelings were recorded using an eight-question $100 \mathrm{~mm}$ visual analogue scale. After collection of the blood sample, the subjects left the laboratory. For the next $13 \mathrm{~h}$ they filled in diet and activity record sheets. Diet was recorded by portion size and activity by intensity and duration. The subjects also collected all the urine they produced until returning to the laboratory for the next set of measurements on the following day. This was again after a $4 \mathrm{~h}$ fast, although water intake was permitted up until $2 \mathrm{~h}$ before arrival. Urine collection, body mass measurement, subjective feelings and blood sample collection took place as before. All these procedures were then repeated for laboratory visits $24 \mathrm{~h}$ and $37 \mathrm{~h}$ after the start of the trials.

During the FR trial, the experimental procedures were identical to those described for the EU trial except that the subjects were requested to abstain from all fluid intake and to ingest foods that had a low water content. They were given a list of foods with a low water content from which they could make choices. The subjects recorded their dietary intake throughout the trial and, from this, the extent of water intake from food intake was established.

Trial order was randomised and the subjects were not informed which trial they were to be taking part in before arrival in the laboratory for the first trial. The subjects undertook the same forms, duration and extent of light physical activity during the two trials. The two trials were undertaken exactly $7 \mathrm{~d}$ apart so that for each subject both trials started on the same day of the week.

For both trials, after providing the final samples at $37 \mathrm{~h}$, a choice of drinks was made available to the subjects. They had free access to these drinks for a period of up to $20 \mathrm{~min}$. The volume of drink consumed after each trial was measured without the subjects' knowledge. Drinking ceased at the subjects' own volition.

\section{Sample, questionnaire and dietary analysis}

The volume of each urine sample was measured, and a $5 \mathrm{ml}$ portion was retained for measurement of electrolyte concentration and osmolality. Part of each blood sample was mixed with anticoagulant $\left(\mathrm{K}^{+}\right.$EDTA; $1.5 \mathrm{mg} / \mathrm{ml}$ ), from which haemoglobin concentration and packed cell volume were determined and plasma was separated for hormone analysis. The remainder of the blood sample was allowed to clot and the serum was separated by centrifugation. Urine and serum were analysed for $\mathrm{K}$ and $\mathrm{Na}$ concentration by flame photometry (Corning 410c; Corning Ltd, Halstead, Essex, UK), chloride concentration by coulometric titration (Jenway PCLM 3; Dunmow, Essex, UK) and osmolality by freezing-point depression (Camlab Roebling Automatik, Cambridge, UK). All urine and serum analyses were carried out in duplicate. The cyanomethaemoglobin method was used for measurement of haemoglobin concentration in duplicate. Packed cell volume was determined by micro-centrifugation in triplicate (Hawksley, Lancing, Sussex, UK). Blood and plasma volume changes were calculated from haemoglobin concentration and packed cell volume values according to the method of Dill \& Costill (1974). Plasma angiotensin II concentration was measured by radioimmunoassay (EuroDiagnostica, Malmo, Sweden) on only five of the fifteen subjects due to technical reasons.

Diets were analysed from the dietary records of ten of the fifteen subjects (Diet 5; RGU, Aberdeen, UK). Five records were not analysed as these were removed from the laboratory before analysis could be undertaken.

\section{Statistical analysis}

Data were analysed for normality of distribution using the Ryan-Joiner test. Two-factor (time and trial) 
repeated-measures ANOVA was used to establish differences between data sets. When differences were discovered in normally distributed data, a Tukey post hoc test or paired $t$ test was used to locate differences. Where differences were detected in non-parametric data, the Kruskal-Wallis and Mann Whitney tests were used to investigate changes over time and the Wilcoxon test was used to identify differences at each time point. Statistical significance was accepted when a $P$ value of less than 0.05 was obtained.

\section{Results}

\section{Initial measurements}

Pre-trial body mass, the volume of urine produced at the initial laboratory visit, the osmolality of this sample and serum osmolality were, for each measure, the same in both trials (Table 1). The subjects also started both trials reporting the same $(P>0.60)$ subjective feelings (Fig. 1). These data indicate that the subjects were in a similar state of euhydration before the start of each trial.

\section{Body-mass changes}

Dietary intake ( $n$ 10) provided an estimated water intake of 478 (SD 335) $\mathrm{ml}$ during FR and 3168 (SD 1167) $\mathrm{ml}$ in the EU trials. During the EU trials, 24 (SD 15) \% of the total water intake was obtained from food $(n 10)$. This resulted in a body-mass loss of 1.9 (SD 0.4$) \mathrm{kg}$ over the $37 \mathrm{~h}$ of FR (Fig. 2) $(P<0.001)$, compared with a non-significant reduction of $0.4(\mathrm{SD} 0.2) \mathrm{kg}$ in the EU trial. The rate of mass loss during FR was significantly greater than in the EU trial $(P<0.001)$ and this rate did not change over the $37 \mathrm{~h}$ of the FR trial $(P=0 \cdot 66)$. Urinary losses amounted to 1.37 (SD 0.39 ) litres over $37 \mathrm{~h}$ of FR accounting for 72 (SD 21) \% of the body-mass loss. This left a body-mass loss of 1081 (SD 420) g accounted for by respiratory, cutaneous and faecal water losses in the FR trial $(n 10)$. Based on the assumption that $1 \mathrm{~g}$ of body-mass loss is equal to $1 \mathrm{ml}$ of water loss, this equates to respiratory, cutaneous and faecal fluid losses over $37 \mathrm{~h}$ of 1.4 (SD 1.5 ) $\%$ of body mass during the FR trial and 1.1 (SD 1.9$) \%$ in the EU trial.

\section{Blood and plasma volume changes}

Plasma volume had decreased to a greater extent by $24 \mathrm{~h}$ $(P<0.01)$ and $37 \mathrm{~h}(P<0.05)$ during the FR trial compared with the corresponding time point in the EU trial (Table 2). Blood volume also decreased to a greater extent during the FR trial $(P<0.005)$.

\section{Serum osmolality and electrolyte changes}

Serum osmolality was significantly elevated at 13, 24 and $37 \mathrm{~h}$ in the FR trial $(P<0.001$; Fig. $2(\mathrm{~B}))$. It reached a maximum at $24 \mathrm{~h}$ in the $\mathrm{FR}$ trial and did not increase further over the next $13 \mathrm{~h}$. Serum osmolality did not change during the EU trial $(P=0 \cdot 18)$ although there was a tendency for it to be higher at the $37 \mathrm{~h}$ time point.

Serum Na concentration followed a similar pattern to serum osmolality (Table 2). Initial serum $\mathrm{Na}$ concentrations were the same in both trials $(P=0.92)$, then at each subsequent time point they were higher in the FR trial compared with the EU trial $(P<0 \cdot 05)$. There was no change in serum $\mathrm{Na}$ concentration during the EU trial.

Serum chloride concentration in the FR trial increased after 13 and $24 \mathrm{~h}(P<0 \cdot 01)$ but not significantly so at $37 \mathrm{~h}$. There was no change in serum chloride concentration during the EU trial (Table 2).

\section{Urine volume}

Lower volumes of urine were produced during the FR trial compared with the EU trial $(P<0.001)$ over the duration of the study (Fig. 3). Although the rate of urine production did not significantly change over the $37 \mathrm{~h}$ in the EU trial, the difference between the 13-24h (the daytime) period and the other two periods almost reached significance $(P=0.05)$. During FR, the rate of urine production during the $24-37 \mathrm{~h}$ period was lower than for the $0-13 \mathrm{~h}$ period $(P=0.03)$.

\section{Urinary electrolyte excretion and osmolality}

The osmolality of urine produced over each collection period was significantly higher in the FR trial compared with the EU trial $(P<0.005)$ (Fig. 3). Urine osmolality did not change during the EU trial $(P>0.05)$. During the FR trial, urine osmolality increased progressively over time and was greater at the $13-24 \mathrm{~h}$ and $24-37 \mathrm{~h}$ time periods than from the $0-13 \mathrm{~h}$ time period $(P<0.05)$.

There was no difference in the total osmotic load excreted in the urine over time in either trial $(P=0.66)$,

Table 1. Pre-exercise measures to indicate hydration status*

(Mean values and standard deviations)

\begin{tabular}{|c|c|c|c|c|c|}
\hline \multirow[b]{2}{*}{ Trial... } & \multicolumn{2}{|c|}{ EU } & \multicolumn{2}{|c|}{ FR } & \multirow[b]{2}{*}{$P$ value } \\
\hline & Mean & SD & Mean & SD & \\
\hline Body mass (kg) & 71.58 & 13.52 & 71.44 & $13 \cdot 68$ & 0.24 \\
\hline Urine volume (ml)) & 225 & 210 & 222 & 150 & 0.97 \\
\hline Urine osmolality (mOsmol/kg) & 308 & 45 & 432 & 88 & 0.22 \\
\hline Serum osmolality (mOsmol/kg) & 281 & 6 & 282 & 4 & 0.87 \\
\hline
\end{tabular}



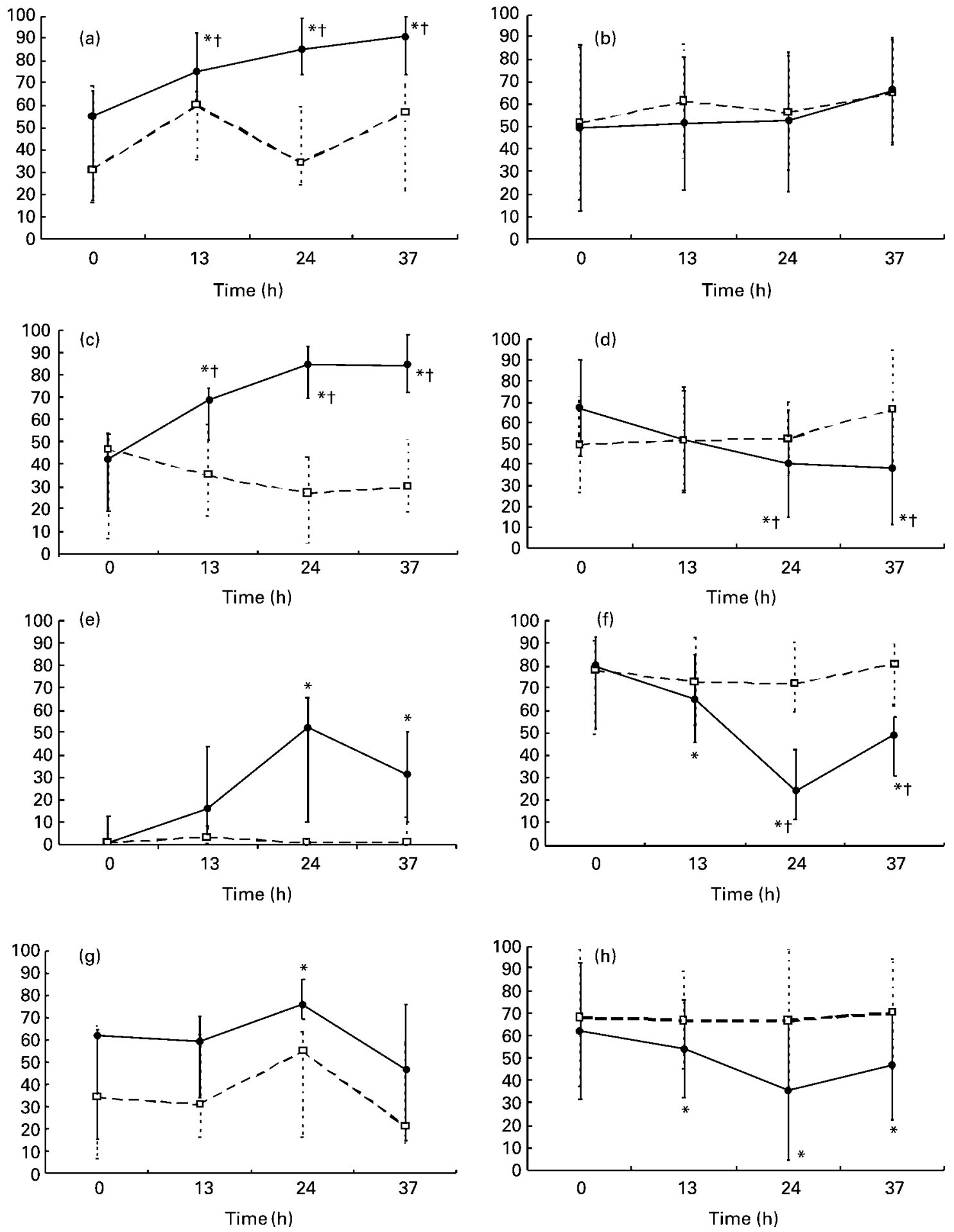

Fig. 1. Subjective feelings: 'How thirsty do you feel now?' (a); 'How hungry do you feel now?' (b); 'How dry does your mouth feel now?' (c); 'How pleasant does your mouth taste now?' (d); 'How sore does your head feel now?' (e); 'How well can you concentrate just now?' (f); 'How tired do you feel just now?' (g); 'How alert do you feel now?' (h). On the visual analogue scale of $0-100 \mathrm{~mm}, 0$ denotes not at all (well), and 100 denotes very (well). Values are means, with standard deviations represented by vertical bars. ${ }^{*}$ Mean rating in the fluid restriction trial (๑) was significantly different to that in the euhydration trial (口) $(P<0.01)$. $†$ Mean rating was significantly different to that at $0 \mathrm{~h}(P<0.05)$.

but it was slightly less in the FR trial (1132 (SD 353) mOsmol) than in the EU trial (1280 (SD 382) mOsmol) $(P=0.030)$. This may reflect the higher energy $(P=0.03)$, protein $(P=0.01)$ or carbohydrate $(P=0.04)$ intake over the $37 \mathrm{~h}$ during the EU trial $(14.5$ (SD 3.7) MJ, 133 (SD
50) g, 452 (SD 123) g) compared with the FR trial $(10 \cdot 3$ (SD 5.0) MJ, 89 (SD 25) g, 310 (SD 186) g).

Urine excretion of $\mathrm{Na}, \mathrm{K}$ and chloride demonstrated similar patterns over time (Table 3). Total $\mathrm{Na}$ excretion was lower $(P<0.05)$ in the FR trial (198 (range 
Time (h)
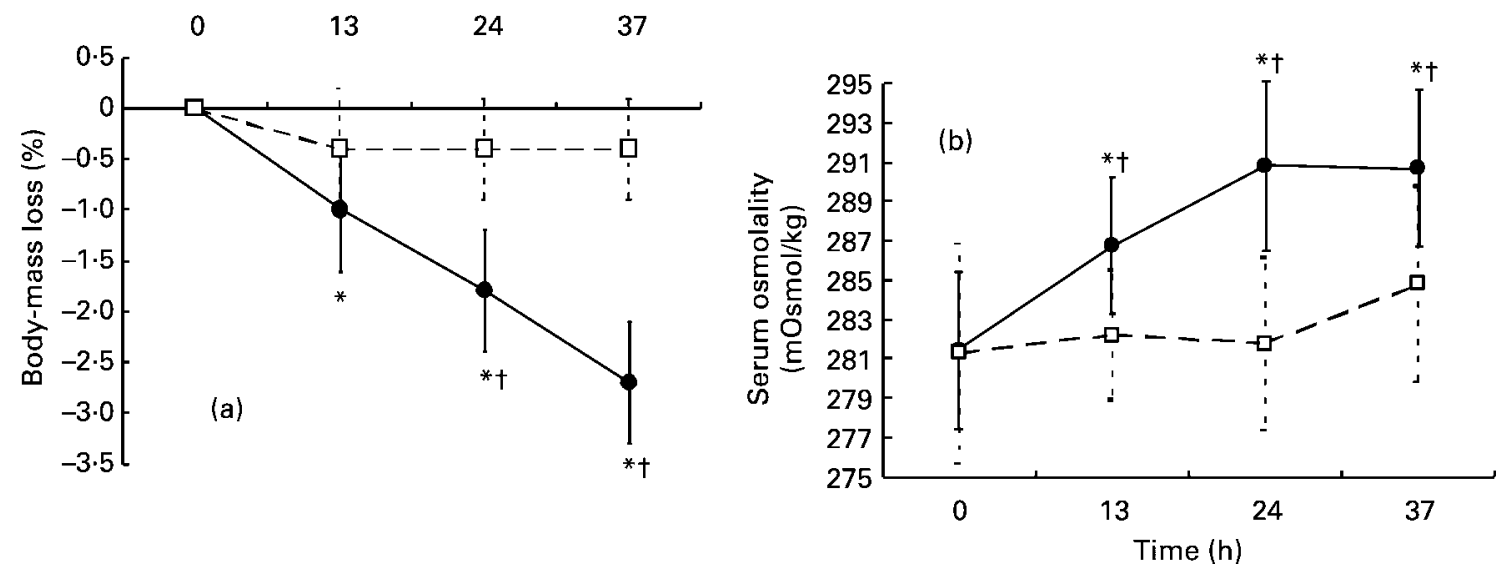

Fig. 2. Changes in body mass (a) and serum osmolality (b) over time in the fluid restriction trial (-) and in the euhydration trial ( $)$.Values are means, with standard deviations represented by vertical bars. *Mean value in the fluid restriction trial was significantly different to that in the euhydration trial $(P<0.05)$. † Mean value was significantly different to that at $0 \mathrm{~h}(P<0.05)$.

Table 2. Plasma volume and serum sodium and chloride concentrationsł (Mean values and standard deviations)

\begin{tabular}{|c|c|c|c|c|c|c|c|c|c|c|c|c|}
\hline \multirow[b]{3}{*}{ Trial... } & \multicolumn{4}{|c|}{ Plasma volume change (\%)§ } & \multicolumn{4}{|c|}{$\begin{array}{l}\text { Serum Na concentration } \\
(\mathrm{mmol} / \mathrm{l})\end{array}$} & \multicolumn{4}{|c|}{$\begin{array}{l}\text { Serum chloride concentration } \\
\qquad(\mathrm{mmol} / \mathrm{l})\end{array}$} \\
\hline & \multicolumn{2}{|c|}{ FR } & \multicolumn{2}{|c|}{ EU } & \multicolumn{2}{|c|}{ FR } & \multicolumn{2}{|c|}{ EU } & \multicolumn{2}{|c|}{ FR } & \multicolumn{2}{|c|}{ EU } \\
\hline & Mean & SD & Mean & SD & Mean & SD & Mean & SD & Mean & SD & Mean & SD \\
\hline 0 & 0 & & 0 & & 142 & 2 & 142 & 3 & 101 & 2 & 100 & 3 \\
\hline $13 \mathrm{~h}$ & $-2 \cdot 4$ & $4 \cdot 1$ & $-1 \cdot 6$ & $3 \cdot 6$ & $144^{\star}$ & 2 & 142 & 2 & $103 \dagger$ & 2 & 102 & 2 \\
\hline $24 \mathrm{~h}$ & $-4 \cdot 2^{*}$ & $4 \cdot 1$ & 0.5 & $2 \cdot 8$ & $147^{*} \dagger$ & 2 & 142 & 2 & $104^{*} \dagger$ & 3 & 101 & 3 \\
\hline $37 \mathrm{~h}$ & $-6 \cdot 2^{*}$ & $5 \cdot 1$ & $-2 \cdot 6$ & $4 \cdot 3$ & $147^{\star} \dagger$ & 4 & 143 & 5 & 103 & 3 & 102 & 3 \\
\hline
\end{tabular}

FR, fluid restriction; EU, euhydration.

* Mean value was significantly different to that for the EU trial $(P<0.01)$

† Mean value was significantly different to that at $0 \mathrm{~h}(P<0.05)$.

‡ For details of subjects and procedures, p. 952.

$\S$ Changes in plasma volume were calculated relative to $0 \mathrm{~h}$.
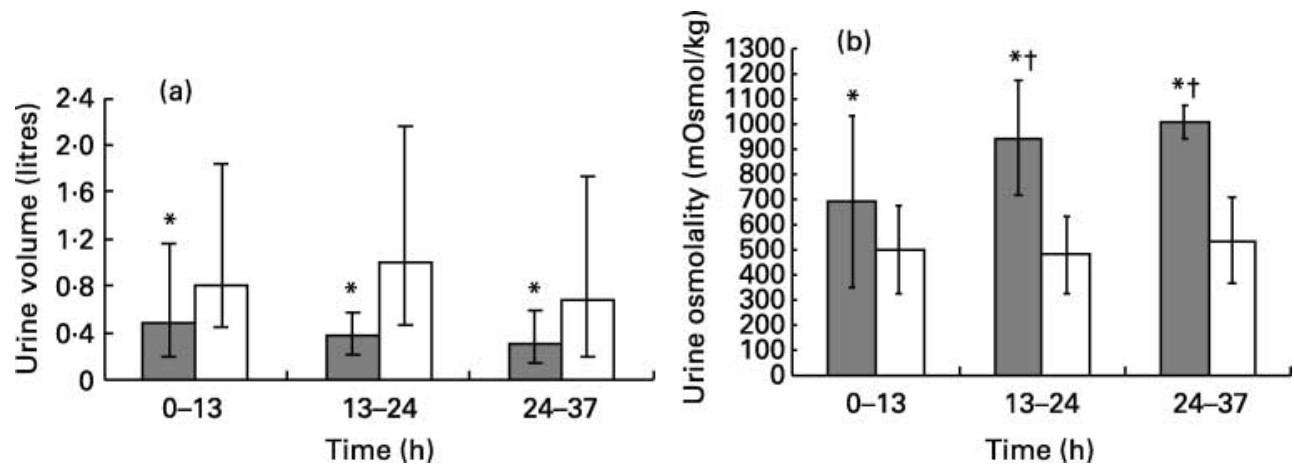

Fig. 3. Total urine production (a) and urine osmolality (b) over each time period. In (a), values are medians, with ranges represented by vertical bars. In (b), values are means, with standard deviations represented by vertical bars. * Median or mean value in the fluid restriction trial ( $\square$ ) was significantly different to that in the euhydration trial $(\square)(P<0.01)$. † Mean value was significantly different to that at $0-13 \mathrm{~h}(P<0.05)$. 
Table 3. Urinary electrolyte excretion (mmol)‡

(Mean values and standard deviations, and medians and ranges)

\begin{tabular}{|c|c|c|c|c|c|c|c|c|c|c|c|c|}
\hline \multirow[b]{3}{*}{ Trial... } & \multicolumn{4}{|c|}{$\mathrm{Na}(\mathrm{mmol})$} & \multicolumn{4}{|c|}{$\mathrm{K}(\mathrm{mmol})$} & \multicolumn{4}{|c|}{ Chloride (mmol) } \\
\hline & \multicolumn{2}{|c|}{ FR } & \multicolumn{2}{|c|}{ EU } & \multicolumn{2}{|c|}{ FR } & \multicolumn{2}{|c|}{ EU } & \multicolumn{2}{|c|}{ FR } & \multicolumn{2}{|c|}{ EU } \\
\hline & Mean & SD & Mean & SD & Median & Range & Median & Range & Median & Range & Median & Range \\
\hline $0-13 \mathrm{~h}$ & 77 & 9 & 91 & 11 & 28 & $11-62$ & 34 & $15-69$ & 60 & $19-122$ & 53 & $30-133$ \\
\hline $13-24 h$ & $80^{\star}$ & 7 & 127 & 11 & $54^{*}$ & $26-83$ & 70 & $31-118$ & $76 \dagger$ & $50-137$ & $99 \dagger$ & $49-272$ \\
\hline $24-37 \mathrm{~h}$ & $67^{\star}$ & 9 & 98 & 13 & 33 & $14-84$ & 37 & $10-57$ & 59 & $27-137$ & 65 & $7-97$ \\
\hline
\end{tabular}

FR, fluid restriction; EU, euhydration.

* Mean or median value was significantly different to that for the EU trial $(P<0.05)$.

† Median value was significantly different to that at $0 \mathrm{~h}(P<0.05)$.

$\ddagger$ For details of subjects and procedures, see p. 952.

103-403) mmol) than in the EU trial (283 (range 148507) $\mathrm{mmol}$ ). There was a tendency for lower $\mathrm{K}$ and chloride excretion during the FR trial, but no significant differences were observed between trials at any time period $(P>0.05)$. Electrolyte excretion was highest during the $13-24 \mathrm{~h}$ time period (daytime) for both trials. The urinary $\mathrm{Na}^{+}: \mathrm{K}^{+}$ratio was significantly lower $(P=0.03)$ in the FR trial $(2.05(\mathrm{SD} 0 \cdot 35))$ than in the EU trial $(2.48(\mathrm{SD} 0.84))$.

\section{Hormones}

Plasma angiotensin II concentration was measured in five subjects, and was significantly higher in the FR trial than in the EU trial at $37 \mathrm{~h}(P=0.04)$. It increased from 9.4 (SD 6.8) pmol/l at $0 \mathrm{~h}$ to $13.4(\mathrm{SD} 4.8) \mathrm{pmol} / \mathrm{l}$ at $37 \mathrm{~h}$ during FR, while remaining unchanged during EU (10.3 $(\mathrm{SD} 6 \cdot 8) \mathrm{pmol} / \mathrm{l}$ at $0 \mathrm{~h}$ and $10 \cdot 3(\mathrm{SD} 5 \cdot 1) \mathrm{pmol} / \mathrm{l}$ at $37 \mathrm{~h}$ ) over the same period.

\section{Subjective feelings}

The subjects started both trials reporting the same $(P>0.60)$ subjective feelings (Fig. 1). There was no change in thirst perception over time in the EU trial $(P=0.78)$, but the perception of thirst was greater than baseline at all times during the FR trial. The feelings of thirst and mouth dryness were also greater during the FR trial than in the EU trial $(P<0 \cdot 05)$. The subjects did, however, differentiate their thirst from hunger. Ratings of hunger were similar in both trials over the study duration in spite of the difference between trials in energy intake.

Feelings of headache were significantly greater at $24 \mathrm{~h}$ $(P<0.005)$ and $37 \mathrm{~h}(P<0.05)$ in the FR trial compared with the EU trial. The subjects also reported that their ability to concentrate and their alertness were reduced in the FR trial and these were significantly lower at each time point than at the corresponding time in the EU trial. The subjects also reported greater difficulty in concentrating as the FR trial progressed $(P<0 \cdot 05)$. They felt significantly more tired at $24 \mathrm{~h}$ during the FR trial than during the control trial $(P=0 \cdot 01)$.

\section{Post-trial fluid intake}

Post-trial fluid intakes were greater after the FR trial (705 (SD 357) $\mathrm{ml}$ ) than after the EU trial (347 (SD 52) ml)
$(P<0.001)$. However, the subjects replaced only 37 (SD 16) \% of their body-mass losses accrued during the FR trial, and stopped drinking despite still being hypohydrated by 1.7 (SD 0.6$) \%$ of their initial body mass.

\section{Discussion}

The subjects experienced a body-mass loss of 1.8 (SD 0.6) \% after $24 \mathrm{~h}$ of FR and this increased to 2.7 (SD 0.6) \% after $37 \mathrm{~h}$ of FR. The rate of body-mass loss did not significantly change over the duration of the study $(P=0.66)$. The bodymass loss resulting from $24 \mathrm{~h}$ FR was similar to that observed in previous studies (Phillips et al. 1984, 1993) where 1.9 (SD 0.3$) \%$ and 1.7 (SD 0.6 ) \% body-mass losses respectively were observed.

The subjects reported a progressively increasing sensation of thirst during the FR trial, although there was no statistically significant change between 13 and $37 \mathrm{~h}$. There was a correlation $(P<0 \cdot 001)$ between feelings of mouth dryness and thirst $\left(R^{2} 0.75\right)$ and between angiotensin II concentration and thirst $\left(R^{2} 0 \cdot 30\right)$. However, there was no correlation between thirst and percentage bodymass losses $\left(R^{2} 0 \cdot 11\right)$, serum osmolality $\left(R^{2} 0 \cdot 10\right)$ or change in plasma volume $\left(R^{2} 0.09\right)$ in the FR trial. The absence of any meaningful association between thirst and these parameters suggests that perception of thirst does not reliably respond individually to each of these factors that might be thought to affect it.

Hyperosmolality has been demonstrated to be related to increases in perception of thirst (Mack et al. 1994) but the lack of correlation between thirst and plasma osmolality in the present study has been observed previously (Seckl et al. 1986). The poor association of the thirst sensation with these individual parameters is unsurprising given Adolph's multiple-factor theory of thirst (Adolph et al. 1954) which proposes that multiple mechanisms act in concert to regulate the sensation of thirst. The degree of dehydration on completion of the FR trial was very high as the subjects replaced only 37 (SD 16)\% of their body-mass losses by voluntary drinking and they remained moderately dehydrated despite the free availability of a variety of fluids. A previous study with $24 \mathrm{~h}$ of FR (Rolls et al. 1980) demonstrated that $65 \%$ of the total fluid consumed over a $1 \mathrm{~h}$ recovery period was ingested within the first $2.5 \mathrm{~min}$ of the hour when water was freely provided. In both cases, subjects would have continued drinking over the 
course of the day to replace their losses gradually. What was clear from these subjects is that they all greatly desired something to drink during the later stages of the study and had to make a conscious effort to abstain from drinking and to continue eating dry foods. These subjects therefore would not have become dehydrated to this extent 'by accident'.

Along with the increased thirst response, the subjects reported greater sensations of discomfort during the FR trial than in the EU trial. Dehydration is probably the predominant factor causing this augmented perception of distress, but it may be that the subjects were also experiencing mild caffeine-withdrawal symptoms (Dews et al. 2002) due to the prohibition on tea and coffee intake during the FR trial. However, from the EU trial diaries, only four of the ten subjects whose diets were analysed would normally have chosen to drink tea or coffee and a further four drank cola or ate chocolate. Also, the quantity of caffeine they consumed was moderate $(152$ (range $8-490) \mathrm{mg} / \mathrm{d}$ ) in comparison with the UK average daily intake (Barone \& Roberts, 1996) reducing the likelihood that these were caffeine-withdrawal symptoms. Nevertheless, FR appeared to have a negative effect on the subjects' perceived ability to function mentally and on their overall feeling of wellbeing.

When the subjects were asked to reduce their water intake by consuming no drinks or liquid foods and to only eat foods with a relatively low water content, they also reduced their overall energy intake by on average $4.2 \mathrm{MJ}(28 \%)$ over the $37 \mathrm{~h}$ study period. This was due to a decrease in carbohydrate and protein consumption. This did not, however, translate into increased feelings of hunger during the FR trial. In our opinion, there is probably more than one reason for the apparent discrepancy between the reported hunger levels and the energy intake. First, our observations of and general discussions with the subjects suggest that they reduced their energy expenditure during the period of FR in comparison with the period of EU. This means that they have the potential to maintain energy balance and hunger levels in the two trials with different energy intakes. While a reduction in energy expenditure of sufficient magnitude to maintain energy balance is unlikely, a trend in this direction is a realistic possibility. This possibility of a reduced energy expenditure during FR fits in with the increased feelings or tiredness and reduced alertness in this trial. When individuals feel tired they are less inclined to exercise. A second possible reason for the apparent discrepancy is the general feeling of malaise the subjects felt during the FR trial. It has been reported that changes in food intake induced by some drugs physiological mechanism is via side effects related to malaise (Halford \& Blundell, 2000).

Clearly there may be an influence of the reduced energy, carbohydrate or protein intake on the subjective feelings reported that cannot be distinguished by the present study design from any influence of hypohydration. However, it remains true that the FR protocol used did influence subjective feelings.

The osmotic load excreted over the $37 \mathrm{~h}$ of the FR trial was 1132 (SD 353) mOsmol. From 24-37 h FR, the osmotic load was 321 (range 141-789) mOsmol. Assuming a maximum urinary concentrating ability of $1200 \mathrm{mOsmol} / \mathrm{l}$ (Zambraski, 1996), a minimum urine production of 267 (range 117-658) $\mathrm{ml}$ would be required to excrete the solute load over the $24-37 \mathrm{~h}$ time period. This would amount to minimal obligatory urine losses of 21 (range 9-51) $\mathrm{ml} / \mathrm{h}$ over this period, which is very similar to the 25 (range $11-63) \mathrm{ml} / \mathrm{h}$ urinary excretion rate observed between 24 and $37 \mathrm{~h}$ in the FR trial. There was no significant difference between the predicted minimum urine production and the actual urine production over the $24-37 \mathrm{~h}$ period in the FR trial $(P=0 \cdot 30)$. These excretion rates were, as expected, far less than that over the $37 \mathrm{~h}$ of the EU trial which amounted to 75 (SD 30) $\mathrm{ml} / \mathrm{h}$. This indicates that between 24 and $37 \mathrm{~h}$ of the FR trial, the subjects' kidneys were near maximally concentrating their urine to minimise fluid losses.

Both male and female subjects were included in the present study. As the average woman has a lower body water content relative to her total body mass, any given bodywater loss expressed as a percentage of body mass represents a greater fraction of her total body water than it would do in the average man of the same mass but with a lower body fat content. The cyclical hormonal variations that occur in women over their menstrual cycle have been associated with water retention and associated increases in body mass in the luteal phase of the cycle. In the present study, however, there was no evidence of this influencing the findings and the female subjects responded no differently to the males.

The average body-mass losses in the EU trial were small (less than $400 \mathrm{~g}$ ) and not significant, and could be explained by several factors. The subjects may have been slightly hyperhydrated upon arrival at the laboratory following the $500 \mathrm{ml}$ water ingestion $2 \mathrm{~h}$ earlier. If this was the case, the tendency for a reduction in body mass in the EU trial may have been due to the subjects returning to their normal euhydrated state. It would be expected, however, that any diuresis to restore EU after a water load would occur within this $2 \mathrm{~h}$ period (Merson et al. 2002). Constraints were placed on the subjects' normal dietary habits during the study (no food and only water ingestion was allowed in the $4 \mathrm{~h}$ before each visit to the laboratory and no water for the $2 \mathrm{~h}$ before arrival). These constraints are therefore the most probable explanation for the body-mass losses during EU in that they may have resulted in the subjects not consuming as much fluid and/or food as they would normally have done.

The greater reduction in plasma and blood volume during the FR trial when compared with the EU trial was expected. The losses were almost linear over time and did not show any tendency to diminish as the subjects became progressively more dehydrated. This was in contrast to the serum osmolality results. Serum osmolality increased nearly linearly between $0-24 \mathrm{~h}$ in the FR trial then no further increase was observed during the remaining 24-37 h period. This increase in serum osmolality with FR was similar to, though slightly greater than, those found previously (Rolls et al. 1980; Phillips et al. 1993). The calculated changes in blood and plasma volume indicate a slight increase in erythrocyte volume over this time period. This indication of an increased intracellular 
volume corresponds with the lack of change in serum osmolality with the concurrent total body water and extracellular volume decrease.

\section{Conclusions}

Significant levels of hypohydration can be induced in healthy volunteers by relatively short periods of voluntary FR. Even though the dehydration induced was relatively minor, it seemed to be sufficient to cause the subjects to report feelings of headache, reduced levels of alertness and greater difficulty concentrating. The subjects also reported feeling more tired. It is well established that physical performance is reduced when individuals are dehydrated by $1-2 \%$ of their body mass and the results of the present investigation suggest that further investigation into other aspects of human wellbeing at these low levels of dehydration may be warranted.

\section{References}

Adolph EF, Barker JP \& Hoy PA (1954) Multiple factors in thirst. Am J Physiol 178, 538-562.

Andersson B (1978) Regulation of water intake. Physiol Rev 58, 582-601.

Barone JJ \& Roberts HR (1996) Caffeine consumption. Food Chem Toxicol 34, 119-129.

Costill DL, Cote R \& Fink W (1976) Muscle water and electrolytes following varied levels of dehydration in man. $J$ Appl Physiol 40, 6-11.

Dews PB, O'Brien CP \& Bergman J (2002) Caffeine: behavioral effects of withdrawal and related issues. Food Chem Toxicol 40, 1257-1261.

Dill DB \& Costill DL (1974) Calculation of percentage changes in volumes of blood, plasma and red cells in dehydration. $J$ Appl Physiol 37, 247-248.
Documenta Geigy, Scientific Tables, 6th ed. [K Diem, editor]. Manchester: Geigy Pharmaceutical Company.

Greenleaf JE (1982) Dehydration-induced drinking in humans. Fed Proc 41, 2509-2514.

Halford JC \& Blundell JE (2000) Pharmacology of appetite suppression. Prog Drug Res 54, 25-58.

Jennett S 2001 The Oxford Companion to the Body, p. 667 [C Blakemore and S Jennett, editors]. Oxford: Oxford University Press.

Lote C 2001 The Oxford Companion to the Body, pp. 416-488 [C Blakemore and S Jennett, editors]. Oxford: Oxford University Press.

Mack GW, Weseman CA, Langhans GW, Scherzer H, Gillen CM \& Nadel ER (1994) Body fluid balance in dehydrated healthy older men: thirst and renal osmoregulation. J Appl Physiol 76, 1615-1623.

Merson SJ, Maughan RJ, Leiper JB \& Shirreffs SM (2002) Changes in blood, red cell and plasma volumes after ingestion of hypotonic and hypertonic solutions. Proc Nutr Soc 61, 108A.

Pedersen RS, Bentzen H, Bech JN \& Pedersen EB (2001) Effect of water deprivation and hypertonic saline infusion on urinary AQP2 excretion in healthy humans. Am $J$ Physiol 280, F860-F867.

Phillips PA, Bretherton M, Risvanis J, Casley D \& Gray L (1993) Effects of drinking on thirst and vasopressin in dehydrated elderly men. Am J Physiol 264, R877-R881.

Phillips PA, Rolls BJ, Ledingham JGG, Forsling ML, Morton JJ, Crowe MJ \& Wollner L (1984) Reduced thirst after water deprivation in healthy elderly men. New Engl J Med 311, 753-759.

Rolls BJ, Wood RJ, Rolls ET, Lind H, Lind W \& Ledingham JGG (1980) Thirst following water deprivation in humans. Am J Physiol 239, R476-R482.

Seckl JR, Williams TDM \& Lightman SL (1986) Oral hypertonic saline causes a transient fall of vasopressin in humans. Am J Physiol 251, R214-R217.

Zambraski EJ (1996) The kidney and body fluid during exercise. In Body Fluid Balance: Exercise and Sport, pp. 75-94 [ER Buskirk and SM Puhl, editors]. Cleveland, OH: CRC Press. 